colleagues $^{8}$ found a similar incidence, though all their patients suffered from clinical diabetes. Assessing the incidence of diabetes in patients with gout on the basis of raised bloodsugar levels (either fasting or during glucose-tolerance tests), T. E. Weiss and colleagues ${ }^{9}$ found an incidence of $28 \%$ (compared with $19 \%$ in controls).

These figures must be viewed in the light of the incidence of diabetes in the general population. In 1963, for example, a working party appointed by the College of General Practitioners reported in this journal that $6.2 \%$ of the population, and no fewer than $14.5 \%$ of those over 50, were found to have a diabetic abnormality of the glucose-tolerance test. ${ }^{10}$ From the results of the Diabetes Survey in Bedford, C. L. Sharp and colleagues ${ }^{11}$ estimate the overall national incidence of diabetes mellitus to be $12-14 \%$.

The incidence of gout in diabetic patients is also of interest. Both Whitehouse and Cleary and A. G. Beckett and J. G. Lewis ${ }^{7}$ found that $1 \%$ of their patients with diabetes mellitus had gout. In general populations of European stock about $0.5 \%$ are found to develop clinical gout, ${ }^{12}{ }^{13}$ and indeed the incidence of hyperuricaemia (above $6 \mathrm{mg}$. per $100 \mathrm{ml}$.) is as high as $13 \%$ in females and $4.6 \%$ in males. ${ }^{12}$

Even if the association between diabetes and gout is not fortuitous the mechanism by which they are related is unknown. Most of the cases of diabetes mellitus have been of the obese "maturity-onset" type, and few have required insulin. Obesity as a causative factor in gout has been noted for many years. I. A. M. Prior and his colleagues, ${ }^{14}$ in a survey of New Zealand Maoris, found a high incidence of hyperuricaemia and clinical gout, diabetic abnormality, and excess weight in both sexes. Diet may raise the serum uric acid by up to $2 \mathrm{mg}$. per $100 \mathrm{ml}$.- -an amount sufficient to produce clinical gout in a previously mildly hyperuricaemic person. ${ }^{15}$ Moreover, the incidence of both the "maturityonset" form of diabetes mellitus and gout rises sharply in late middle age.

What chemical mechanisms could relate gout and diabetes mellitus ? Firstly, uric acid has a chemical similarity to

\footnotetext{
Whytt, R., The Works of Robert Whytt, 1768, pp. 557, 708. Edin-

- Trousseau, A., Lectures on Clinical Medicine, 1870, Vol. 3, p. 497. New Sydenham Society, London.

- Garrod, A. B., A Treatise on Gout and Rheumatic Gout, 1876, 3rd ed., p. 472. London.

- Charcot, J. M., Clinical Lectures on Senile and Chronic Diseases, 1881, p. 99. New Sydenham Society, London.

- Whitehouse, F. W., and Cleary, W. J., jun., f. Amer. med. Ass., 1966, $197,73$.

- Herman, j. B., Metabolism, 1958, 7, 703.

- Beckett, A. G., and Lewis, J. G., Quart. F. Med., 1960, 29, 443.

- Ishmael, W. K., Owens, J. N., jun., Payne, R. W., and Honick, M. D., F. Amer. med. Ass., 1964, 190, 396.

- Weiss, T. E., Segaloff, A., and Moore, C., Metabolism, 1957, 6, 103.

10 Report of a Working Party appointed by the College of General PractiReport of a Working Party appointed by
tioners, Brit. med. f., 1963, 2, 655.

" tioners, Brit. med. F., 1963, 2, 655. Med., 1964, 57, 193.

12 Popert, A. J., and Hewitt, J. V., Ann. rheum. Dis., 1962, 21, 154.

Lennane, G. A. Q., Rose, B. S., and Isdale, I. C., ibid., 1960, 19

" 120. Prior, I. A. M., Rose, B. S., and Davidson, F., Brit. med. 7., 1964,

1s Dixon, A. St. J., in Progress in Clinical Rheumatology, ed. A. St. J. Dixon. 1965. London.

10 Griffiths, M., $\dot{f}$. biol. Chem., 1950, 184, 289.

: Dunn, J. S., Sheehan, H. L., and McLetchie, N. G. B., Lancet, 1943

1. Collins-Williams, J., and Bailey, C. C., Proc. Soc. exp. Biol. (N.Y.),

1949, 71, 583.

oldfinger, S., Klinenberger, J. R., and Seegmiller, J. E., ibid.. 1965 272, 351 .

¿ Scott, J. T., McCallum, F. M., and Holloway, V. P., Clin. Sci., 1964, 27, 209.

2 Berkowitz, D., f. Amer. med. Ass., 1966, 197, 77.

ss - ibid., 1964, 190, 856.

* Bartels, E. C., Balodimos, M. C., and Corn, L. R., Med. clin. N. Amer., 1960, 44, 433.
}

alloxan, ${ }^{16}$ which can induce diabetes by necrosis of the $\beta$-cells of the islets of Langerhans. ${ }^{17}$ And, though large injections of uric acid have been reported to induce diabetes in rabbits in certain circumstances, ${ }^{16}$ similar experiments ${ }^{18}$ failed to confirm this result. Thus a diabetogenic effect of uric acid remains unproved. Secondly, it is known that ketoacidosis will produce hyperuricaemia by reducing the renal clearance of urate. This can be seen in cases of diabetic ketoacidosis ${ }^{19}$ by giving infusions of ketones into normal persons ${ }^{20} 21$ and by starvation of normal persons. ${ }^{21}$ But since gout frequently develops before the diabetes, and since the diabetes, when it occurs, is usually mild, this explanation seems unconvincing.

A third possible chemical mechanism has been described by $\mathrm{D}$. Berkowitz. ${ }^{22}$ In 1964 he reported ${ }^{23}$ a correlation between hyperuricaemia and hypertriglyceridaemia, and he now proposes that there is a primary association between hypertriglyceridaemia and reduced glucose tolerance. ${ }^{22}$ This suggests a possible link between hyperuricaemia and diabetes through an abnormality of triglyceride metabolism. He may be right, though perhaps changes common to both diabetes mellitus and gout-for example, obesity and increasing age -could themselves produce abnormalities of triglyceride metabolism.

The development of diabetes has been said to improve clinical gout, ${ }^{24}$ and it is interesting that Garrod noted this in $1876 .^{3}$ Conversely hyperuricaemia may diminish the clinical expression of diabetes. ${ }^{5}$ Ishmael and his colleagues ${ }^{8}$ claim that before 1944 diabetes was rarely seen in association with gout, and some of the recent reports have suggested that the lowering of the serum uric acid level by modern uricosuric drugs could be revealing the diabetic state. There is certainly no evidence that uricosuric drugs are themselves diabetogenic.

It would seem clear that the association of gout and diabetes mellitus is not uncommon. Whether it is fortuitous or not, it might be advisable to add blood-sugar estimations to the routine investigations of a patient with gout.

\section{Diffuse Interstitial Pulmonary Fibrosis}

Two decades have passed since the last of three papers by L. Hamman and A. R. Rich ${ }^{1}$ brought to light a previously unrecognized disorder-namely, diffuse interstitial pulmonary fibrosis. In that time it has become apparent, from many published reports, that the acute form which they described is less common than the chronic form. The disease is now known to occur at all ages and even in infancy. Only very occasionally does the patient recover. The diagnosis need not now await necropsy; it can be made with some confidence in life on clinical and radiological findings, and in typical cases even lung biopsy has become unnecessary.

An excellent review by J. L. Livingstone and colleagues ${ }^{2}$ outlined the development of our knowledge of the subject and described 45 cases in adults. The story is nearly always of progressive dyspnoea with an irritable dry cough but no fever. In the lungs post-tussive rales are heard without expiratory wheezing. Clubbing of the fingers (in two-thirds of the

\footnotetext{
1 Hamman, L., and Rich, A. R., Bull. Fohns Hopk. Hosp., 1944, 74, 177.

Livingstone, J. L., Lewis, J. G., Reid, L., and Jefferson, K. E., Quart. F. Med., 1964, 33, 71

Midwinter, R E., Apley, J., and Burman, D., Arch. Dis. Childh., $1966,41,295$.
} 
cases), loss of weight, and vague chest pains are common. The characteristic $x$-ray appearance is mottling (which usually starts in the lower zones and progressively spreads and becomes coarser) with or without "cystic" translucencies. Studies of pulmonary function show a fundamental impairment of gas transfer. Lung biopsy has shown that the disorder evolves from early alveolar thickening through increasing fibrosis to " honeycomb lung."

In the final stages the patient is cyanosed and tachypnoeic at rest. Death from respiratory failure or from cardiac failure (which the clinician may mistakenly consider to be primary) usually occurs in two to six years, though it can be much quicker. Occasionally the process scems to be static, and there are extremely rare authenticated cases of spontaneous recovery. While corticosteroid treatment is usually ineffectual, it is the only therapy that holds any promise. Some patients feel better on it, but in very few is the clinical improvement definite or radiological clearing of the mottling complete. R. E. Midwinter, J. Apley, and D. Burman, ${ }^{3}$ listing the cases which have been described in children, give details of a 13-year-old boy in whom the original diagnosis was proved by lung biopsy, and whose full clinical and radiological recovery was confirmed by pulmonary-function studies a year after treatment with prednisolone had been stopped.

Nothing is known of the cause (or causes) of diffuse intc:stitial pulmonary fibrosis, though there is an occasional association with rheumatoid arthritis. Perhaps this deficiency will be remedied now that the disorder is being recognized increasingly by clinicians without waiting for the pathologist to make the diagnosis.

\section{Sedation in Early Labour}

Though childbirth should surely be an enriching and natural experience in normal circumstances, women differ considerably $^{1}$ in their reaction to the pain and distress of labour. The amount of sedation and analgesia that a woman requires varies enormously, and should be determined by the patient's attitude to her labour rather than by any philosophical views on the ennobling effects of suffering which may be held by her obstetrician. Those who seek oblivion should be given it. ${ }^{2}$

Before labour begins chloral hydrate or barbiturates can be used to help the patient to sleep. Once labour is established these are less desirable, as their action is not reversible. Scopolamine has still a place in the management of incoordinate types of labour, but should no longer be given with morphine because the combination causes marked inhibition of respiration in the newborn child. There is no place for bromide mixtures in modern obstetrics.

In normal labour pain can be relieved by morphine or pethidine, but both these drugs can produce respiratory depression in the baby. For this reason morphine is used less commonly than pethidine and is given only to primigravida in the early stages of labour. Pethidine has a wider margin of safety-doses of up to $250 \mathrm{mg}$. intramuscularly can be given-but even when pethidine is used alone depression of respiration can still be a problem. Nalorphine and levallorphan act as antagonists to this depressant action of morphine and pethidine, and can be given to the mother or to the infant after birth. A mixture of pethidine and levallorphan (Pethilorfan) is now used widely in domiciliary ohstetrics, but because of their different lengths of action these

two drugs are better given separately. Unless pethidine is given intravenously, doses of less than $125 \mathrm{mg}$. are rarely adequate to relieve the pain of labour, but some reduction of this dose is possible if tranquillizers are given as well. ${ }^{3}$ On no account should morphine or pethidine be given to a patient who is taking a monoamine oxidase inhibitor such as phenelzine or nialamide, as this combined therapy causes circulatory collapse which can result in death. ${ }^{45}$

Drugs of the phenothiazine group also are used in labour and appear to be safe. Those commonly given are compounds having a dimethylaminopropyl side chain ${ }^{6}$-namely, chlorpromazine, promazine, and promethazine. Less widely used are substances with piperazine side chains, prochlorperazine, trifluoperazine, and perphenazine. These drugs enhance the action of pethidine, particularly when given in an intravenous infusion, ${ }^{37}$ but the benefits are slight, and reports of controlled studies have been less enthusiastic than those of earlier uncontrolled assessments. ${ }^{8}$

Promethazine is said to shorten labour ${ }^{9}$ and rapidly disappears from the maternal circulation without reaching the foetus. ${ }^{10}$ However, the babies do not seem to be in better condition at birth after promethazine than when no tranquillizer has been given. ${ }^{11}$ T. G. Gready and his colleagues ${ }^{12}$ state that perphenazine, given with pethidine and scopolamine, reduces the incidence of distress in newborn infants. Other investigators disagree but confirm that the type and length of labour are unchanged. ${ }^{13}$ Phenothiazine drugs, and in particular perphenazine, help to prevent vomiting in labour. ${ }^{14}$ is There are few side-effects from phenothiazines. Chlorpromazine causes a fall in blood pressure in about $20 \%$ of patients, ${ }^{16}$ and this hypotension can be serious. ${ }^{17}{ }^{18}$ Promazine also lowers the blood pressure, but only when used with regional anaesthesia; other members of the group seem to be free from this defect. Foetal tachycardia can occur; occasionally there is a delayed effect upon the child, who may become unresponsive several hours after birth. ${ }^{2}$

Preparation during the antenatal period is of great importance. Patients who are calm on admission to the labour ward respond to drugs better than those who enter hospital already distressed. ${ }^{11}$ The most valuable function of drug therapy is to render the patient more accessible to suggestion. ${ }^{19}$

"Important as drugs are, it is profoundly unrealistic to view obstetric analgesia merely in terms of their administration. They can be excellent supplements to good management but can never supplant it.",2

\footnotetext{
Katz, M. M., in Obstetritiis et Gynaecologia, edited by F. T. Evaus and T. C. Gray, 1965, 2nd Interisational Congress, Vienna.

Ransom, S., General Anaesthesia, 2nd ed., 1965. London.

MacVicar, J., and Murray, M. H., Brit. med. F., 1960, 1, 595

London, D. R., and Milne, M. D., ibid., 1962, 2, 1752 .

Pells Cocks. D., and Passmorc-Rowe, A., ibid., 1962, 2, 1545.

Dundee, J. W., Moore, J., Love, W. J., Nicholl, R. M., and Clarke, R. S., Brit. 7. Anaesth., 1965, 37, 332.

Pollock, G. B., Spitzer, J. J., and Mason, D. J., Obstet. and Gynec. $1960,15,504$.

1960, 15, 504. B. Brit. med. 7., 1963, 2, 423.

Ecker!ing, B., Goldman, J. A., and Gans, B., Obstet. and Gynss $1959,14,331$

Adelman, M. H., Fisch, H., Jacobson, E., and Katz, J., Anesthesiolu. $\%$ $1958,19,93$.

Fowe, C. E., Kiem, I. M., Fromhagen, C., and Cavanagh, D., f. Anie med. Ass., 1962. 181, 290.

Gready, T. G., Estrada, W. J., and Haden, J., Amer. F. Obstet. Gynr $1959,77,412$.

${ }^{13}$ Gordon, E. M., and Nelson, H. B., ibid., 1965, 92, 299.

"Anderson, G., Albert, C., Henley, E., Witten, S., Winshel, A., arit Albert, S., Obsiet. and Gynec., 1959, 13, 504.

Phillips, O. C A ibid., $1960,15,182$.

16 Harer, W. B., ibid., 1956, 8, 1

i Schaffer. A. L., Amer. F. Obstet. Gynec., 1956, 71, 1247.

Sprague, L. D., Obstet and Gynec. 1957, 9, 633

Lámbert. P. A., Encépha!e. 1965, 54. 352
} 